\title{
A PÓS-GRADUAÇÃO STRICTO SENSU EM DIREITO NO BRASIL, EXPANSÃO, DESIGUALDADE, NUCLEAÇÃO E SOLIDARIEDADE: $O$ PROTAGONISMO DO PPGD/UFPE A PARTIR DO ANO DE 1996
}

\author{
Raymundo Juliano Rego Feitosa ${ }^{1}$
}

Introdução

A proposta deste estudo está dividida em cinco partes. A primeira remete a uma descrição do sistema de Pós-graduação stricto sensu no Brasil. A segunda dimensão busca realizar uma descrição e análise do sistema de Pós-graduação stricto sensu em Direito; a terceira, examinará a rede de Pós-graduação em Direito e sua expansão no cenário de desigualdade e regionalização.

Por fim, a quarta e última parte tem, por escopo, analisar a chamada nucleação acadêmica ou, mais precisamente, verificar o protagonismo de programas de Pós-graduação stricto sensu na área do Direito, evidenciando aqueles que se destacaram na condição de influenciadores. E, em especial, realizar uma análise da atuação efetiva e do protagonismo do PPGD/UFPE, notadamente no período compreendido entre 2000 a 2010, buscando caracterizar a inserção do programa no âmbito regional e também nacional.

Do ponto de vista da metodologia, a ideia básica por trás do conceito de rede social é a de conectividade. Vale dizer, trata-se de uma específica estrutura, a qual contém em seu interior elementos sociais interligados por força de certas relações ou de certos fluxos, cuja totalidade das relações sociais encontra nesta estrutura a sua dimensão, os seus limites e a sua constituição enquanto fenômeno social.

\footnotetext{
Possui graduação em Direito pela Faculdade de Direito de Caruaru (1974), mestrado em Sociologia pela Universidade Federal de Pernambuco (1978) e doutorado em Direito - Universidad Autonoma de Madrid (1993). Pós-Doutorado na Universidad Castilla La Mancha (2005). É Coordenador do Programa de PósGraduação em Direito (Mestrado e Doutorado) da Universidade Católica de Pernambuco (UNICAP), onde leciona na graduação e na pós-graduação. Também é professor da Universidade Estadual da Paraíba (UEPB). Tem experiência na área de Direito, com ênfase em Direito Tributário e Financeiro, atuando principalmente nos seguintes temas: federalismo, reforma tributária, sistemas tributários, tributação indutora e intervenção econômica. Foi Professor Visitante nas Universidades de Salamanca e Castilla la Mancha na Espanha. Foi professor adjunto da Universidade Federal de Pernambuco e coordenou o Programa de Pós-Graduação em Direito (Mestrado e Doutorado) da Universidade Federal de Pernambuco. Foi professor adjunto da Universidade do Estado do Amazonas - UEA (docente no Programa de PósGraduação em Direito Ambiental). Presidiu o CONPEDI em quatro mandatos (2003/2005, 2005/2007, 2013/2015 e 2015/2017).
} 


\section{A Pós-Graduação stricto sensu no Brasil}

Um estudo realizado em 2009 por duas pesquisadoras da UFPE, fixou que:

Partindo da consideração de que os cursos de mestrado e doutorado constituem um lugar privilegiado de produção do conhecimento, dada a centralidade que a pesquisa científica deve neles assumir, este artigo problematiza a questão em foco a partir de uma análise da política para a pós-graduação em educação no Brasil. Assim, analisaremos a trajetória da pós-graduação brasileira e a inserção e evolução da pesquisa educacional no interior desse processo. Essa estratégia visa apontar o lugar dos estudos sobre política educacional no seio dos programas de pós-graduação em educação, buscando desvelar a sua emergência e consolidação como objeto de investigação. Nossas reflexões, com base em construto teórico de Pierre Bourdieu, ${ }^{2}$ têm por suposto que a política educacional, como de resto toda política pública, não se constrói num vazio. Como resultado da ação humana, é definida e implementada em estreita articulação com o contexto sociopolítico, econômico e cultural do qual emerge. Portanto, sofre as influências de embates políticos, dos conflitos e contradições próprios de uma sociedade de classes, bem como do universo cultural e simbólico peculiar à nossa realidade, dimensões que se apresentam intimamente articuladas. ${ }^{3}$

É importante observar que, com base em Pierre Bourdieu ${ }^{4}$, as reflexões das autoras admitem como ponto de partida que a política educacional, bem como os demais âmbitos das políticas públicas não são construídas num vácuo. Pelo contrário, são necessariamente vinculadas ao contexto econômico, político, social e cultural. Daí, que a política educacional vem receber os impactos próprios dos conflitos existentes nos âmbitos suprarreferidos.

Como já é de amplo conhecimento os problemas enfrentados pelo ensino superior no Brasil são sobejamente identificados. Portanto a universidade brasileira e sua Pós-Graduação refletem necessariamente tais problemas, que exigem profundas mudanças na educação brasileira. ${ }^{5}$

2 BOURDIEU, Pierre. O campo científico. In: ORTIZ, Renato (org.). A sociologia de Pierre Bourdieu. São Paulo: Olho D'água, 2003, p. 112-143.

3 SANTOS, Ana Lúcia Felix dos; AZEVEDO, Janete Maria Lins de. A pós-graduação no Brasil, a pesquisa em educação e os estudos sobre a política educacional: os contornos da constituição de um campo acadêmico. Revista Brasileira de Educação, v. 14 n. 42 set./dez. 2009, p. 334.

4 BOURDIEU, Pierre

5 MORITZ, Gilberto de Oliveira; MORITZ, Mariana Oliveira; MELO, Pedro Antônio de. A Pós-Graduação brasileira, cit. p.1. 2011. 
Mesmo reconhecendo o enorme sucesso obtido pela Pós-Graduação brasileira, impõe-se também admitir que ela está diante de imensos desafios, oriundos das políticas de governo, das dificuldades na internacionalização e em especial nas marcadas diferenças regionais.

Fora de dúvidas que o sistema de Pós-graduação do Brasil recebe reconhecimento da comunidade científica no Brasil e fora dele.

A evolução e expansão contínuas associadas a padrões de qualidade, já podia ser expressa em 2008, pelo que consta no quadro I, abaixo:

\section{Quadro 1: Cursos de mestrado e doutorado reconhecidos pela CAPES,} por região geográfica

\begin{tabular}{|l|r|r|r|r|r|r|r|r|r|}
\hline \multirow{3}{*}{ Região } & \multicolumn{4}{|c|}{$\begin{array}{c}\text { Programas e cursos } \\
\text { de pós-graduação }\end{array}$} & \multicolumn{4}{c|}{$\begin{array}{c}\text { Totais de cursos } \\
\text { de pós-graduação }\end{array}$} \\
\cline { 2 - 11 } & Total & $\mathrm{M}$ & $\mathrm{D}$ & $\mathrm{F}$ & $\mathrm{M} / \mathrm{D}$ & Total & $\mathrm{M}$ & $\mathrm{D}$ & $\mathrm{F}$ \\
\hline $\begin{array}{l}\text { Centro- } \\
\text { Oeste }\end{array}$ & 184 & 93 & 2 & 17 & 72 & 256 & 165 & 74 & 17 \\
\hline Nordeste & 456 & 249 & 14 & 37 & 156 & 612 & 405 & 170 & 37 \\
\hline Norte & 110 & 68 & 2 & 6 & 34 & 144 & 102 & 36 & 6 \\
\hline Sudeste & 1.316 & 399 & 18 & 122 & 777 & 2.093 & 1.176 & 795 & 122 \\
\hline Sul & 522 & 242 & 5 & 43 & 232 & 754 & 474 & 237 & 43 \\
\hline Brasil & 2.588 & 1.051 & 41 & 225 & 1.271 & 3.859 & 2.322 & 1.312 & 225 \\
\hline
\end{tabular}

Fonte: MEC/CAPES. Última atualização: 15 de maio de 2008.

Legenda: M: mestrado acadêmico; D: doutorado; F: mestrado profissionalizante.

Programas: M/D - Mestrado acadêmico/doutorado.

(Elaborado por: Ana Lúcia Felix dos Santos e Janete Maria Lins de Azevedo)

A história da Pós-graduação, conforme o que mostra no quadro I acima, evidencia um processo de expansão notável e, por outro lado, deixa patente uma das identidades do sistema de Pós-Graduação do Brasil, qual seja, uma fortíssima assimetria de aspecto regional.

Vale salientar que as assimetrias não apenas existem no plano quantitativo, pois no aspecto qualitativo também são constatáveis.

Rigorosamente, mais de $60 \%$ dos cursos/programas, estão localizados nas regiões: sul e sudeste.

$6 \quad$ SANTOS, Ana Lúcia Felix dos; AZEVEDO, Janete Maria Lins de. A pós-graduação no Brasil, a pesquisa em educação e os estudos sobre a política educacional: os contornos da constituição de um campo acadêmico. Revista Brasileira de Educação, v. 14 n. 42 set./dez. 2009, p. 335. 
Torna-se imperioso observar que, como chama a atenção Santos e Azevedo, ${ }^{7}$ a Pós-graduação brasileira surge nos anos 60, mais precisamente com o parecer n ${ }^{\circ} 977$ de 1965, que ficou conhecido como parecer Sucupira. E ainda hoje, autores existem que realçam a importância do parecer quando a questão em debate está referida à sistematização da Pós-Graduação no Brasil.

Em uma avaliação sobre a evolução da Pós-Graduação no Brasil, Nobre e Freitas ${ }^{8}$ buscaram descrever a história da Pós-Graduação articulada ao processo de avaliação dos cursos de mestrado e doutorado, bem como aos programas nacionais de Pós-Graduação a partir 1975 até o último Plano Nacional de Pós-Graduação (PNPG 2011-2020). Avaliam ainda o papel da CAPES e do CNPQ, tanto na evolução qualitativa, quanto na quantitativa.

\section{A Pós-Graduação stricto sensu em Direito}

Um dos melhores modos de compreender o panorama atual da PósGraduação stricto sensu em Direito é através do Relatório de Avaliação do ano de 2013 da CAPES, discutido e escrito por docentes de diversos programas.

Segundo esse relatório, "a Área de Direito caracteriza-se pelo forte envolvimento de seus corpos docente e discente em agendas políticas e sociais, seja na perspectiva local, regional e nacional, e, para parte significativa da área internacional". 9

Isto significa que parte considerável da produção intelectual (seja em artigos, capítulos de livros, dissertações ou outras formas) enfrenta tais debates relacionando os aspectos teóricos com a efetivação dos direitos, o papel do Supremo Tribunal Federal, as políticas públicas, efetividade da democracia e diversas outras questões políticas atuais.

Há considerável heterogeneidade dos programas devido a questões geográficas, culturais e econômicas, sendo as regiões Sul e Sudeste as que possuem a maior quantidade de programas, e em número muito superior aos das regiões Norte, Nordeste e Centro-Oeste, mesmo quando somadas. ${ }^{10}$ Isto gera um desafio à expansão da pós-graduação e à formação de docentes de maneira equilibrada e autônoma em todo país.

Outra notória característica da área e que, naturalmente, repercute na pesquisa e nos programas de Pós-Graduação, reside no fato de que é comum o acúmulo

Idem, ibidem.

8 Nobre, L. N., \& Freitas, R. R. (2017). A evolução da pós-graduação no brasil: histórico, políticas e avaliação. Brazilian Journal of Production Engineering - BJPE, 3(2), 26-39. https://doi.org/10.0001/ v3n2 3.

9 CAPES - Coordenação de Aperfeiçoamento de Pessoal de Nível Superior. Cursos Recomendados/ Reconhecidos. Op. cit. Op. cit. p. 1-2, 2013.

10 PRADO, Edna Cristina do; SANTOS, Clecia Maria dos; PEREIRA JÚNIOR, Antonio Miguel. Pósgraduação stricto sensu em Direito: onde e como se forma o docente dos cursos de graduação. $R B P G$, Brasília, v. 12, n. 28, p. 448, agosto de 2015. 
da profissão de professor com outra profissão jurídica existente (promotor, procurador, juiz, advogado etc.). Com efeito, por muito tempo, os profissionais de destaque, principalmente os que ocupavam cargos públicos prestigiados, eram preferidos para o exercício da docência já que, supostamente, os alunos aprenderiam algo a mais devido à sua experiência prática bem-sucedida. Entretanto, recentemente instituiu-se medidas para reduzir esta característica e, assim, valorizar os professores com dedicação integral e perfil acadêmico, tendo em vista que, muitas vezes, à docência e a pesquisa tornavamse prejudicadas em virtude da pouca importância que se lhes eram dadas.

Conforme assinalado na avaliação trienal de 2013, o objetivo primordial dos programas de Pós-Graduação stricto sensu em Direito consiste em formar recursos humanos com habilitação e qualificação necessárias para:

a) ensinar fundamentos teóricos e metodológicos do Direito, contemplando quer a produção bibliográfica clássica, quer contemporânea em níveis de graduação e de Pós-Graduação;

b) desenvolver com autonomia projetos de pesquisa científica;

c) divulgar os resultados de pesquisa em eventos acadêmicos, em livros, capítulos de livros e em periódicos científicos devidamente qualificados;

d) orientar graduandos e pós-graduandos (em níveis de mestrado e de doutorado), com vistas à formação de novos pesquisadores;

e) contribuir para a construção institucional de novos programas de Pós-Graduação stricto sensu, de novos núcleos e projetos de pesquisa científica;

f) divulgar conhecimento científico para públicos não acadêmicos, visando a difusão do conhecimento e a efetiva realização do ordenamento jurídico nacional, e a concretização dos direitos dos cidadãos. ${ }^{11}$

Sabemos hoje que os cursos de mestrado no Brasil foram idealizados na forma de mestrado acadêmico, que possuem como finalidade básica aprofundar conhecimentos científicos com o propósito de formar professores e pesquisadores para o ensino superior.

Por último, vale assinalar que os Mestrados Profissionais regulamentados em 2009 atribuem prerrogativas de graus idênticos ao do Mestrado Acadêmico, habilitando também para a docência.

11 ALMEIDA, Elizangela Santos de. A formação stricto sensu dos professores dos cursos de direito e seus reflexos no ensino jurídico. Dissertação (Mestrado em Educação) - Universidade de Uberaba - UNIUBE, Uberaba, p.63-64. 2014. 
3. A rede de Pós-Graduação stricto sensu em Direito: desigualdade e regionalização

Dois estudos que tem como objeto a Pós-Graduação em Direito no Brasil são de referência obrigatória: o de Marcelo Varella, ${ }^{12}$ e o de Gameiro e Guimarães Filho ${ }^{13}$ e nos valemos deles para mensurar papéis e funções de programas de Pós-Graduação concedendo um olhar especial aos existentes na região Nordeste.

$\mathrm{O}$ primeiro dos citados teve como base de dados os informes prestados à CAPES (à época ainda não avaliados) em 2012. É importante assinalar que o artigo foi escrito em 2014 e somente publicado em fevereiro de 2016. Do ponto de vista teórico, a questão central é a chamada "nucleação acadêmica", e no caso, esta foi avaliada a partir de dois indicadores:

O primeiro é que seus egressos se tornem professores em outros programas de mestrado e doutorado. O segundo é a influência direta do conhecimento nela produzido na construção do saber em uma determinada área. ${ }^{14}$

Cabe ressaltar o posicionamento crítico do autor, quando faz uma avaliação do modelo de academia existente no Brasil:

Os centros mais influentes de produção de conhecimento, conhecidos como centros nucleadores, têm um dever social de pensar a pós-graduação do Brasil como um todo, de criar padrões de qualidade nacionais e políticas institucionais de influência nacional. Estes cursos são premiados com o conceito 6 e 7 da CAPES. ${ }^{15}$

Quanto à metodologia adotada, consistiu no seguinte: analisar o corpo docente dos programas de Pós-Graduação em Direito existente no Brasil em 2012, ou seja, aqueles que preencheram o Coleta/CAPES, mesmo que não avaliados. Ato contínuo, consistiu na tarefa de identificar a instituição, na qual cada docente obteve sua maior titulação.

Em síntese, para esta investigação o interesse fundamental está nas instituições existentes no Nordeste.

$\mathrm{Na}$ região Nordeste, as instituições de ensino analisadas foram: Centro Universitário do Maranhão (UNICEUMA), Universidade Católica de Pernambuco

\footnotetext{
12 VARELLA, Marcelo. Quem influencia a pós-Graduação em Direito no Brasil? Uma análise empírica da nucleação acadêmica. Revista de Direito Brasileira, v. 12, p. 112, 2015.

13 GAMEIRO, Ian Pimentel; GUIMARÃES FILHO, Gilberto. O mapa da pós-graduação em Direito no Brasil: uma análise a partir do método da Social Network Analysis, v. 13 n. 3, 2018. Disponível em: http:// bibliotecadigital.fgv.br/ojs/index.php/revdireitogv/article/view/73332/70471. Acesso em: 23 nov. 2020.

14 VARELLA, Marcelo. Quem influencia a pós-Graduação em Direito no Brasil? Cit, p. 112, 2015.

15 Idem, ibidem, p. 112, 2015.
} 
(UNICAP), Universidade de Fortaleza (UNIFOR), Universidade Federal da Bahia (UFBA), Universidade Federal Da Paraíba (UFPB), Universidade Federal de Alagoas (UFAL), Universidade Federal de Pernambuco (UFPE), Universidade Federal de Sergipe (UFS), Universidade Federal do Ceará (UFC), Universidade Federal do Maranhão (UFMA) e Universidade Federal do Rio Grande do Norte (UFRN).

A análise realizada permitiu constatar quais foram as instituições nucleadoras dos programas suprarreferidos, destacando, inclusive, os percentuais dos titulados por programas representativos, conforme fixado a seguir:

UNICEUMA: $46,15 \%$ dos docentes são titulados pela PUC-SP; $23,08 \%$ dos docentes são titulados pela UFPR; UNICAP: $58,33 \%$ dos docentes são titulados pela UFPE; $16,67 \%$ dos docentes são titulados pela Universidade de Lisboa; UNIFOR: $40 \%$ dos docentes são titulados pela UFPE; $10 \%$ dos docentes são titulados pela UFMG; UFBA: 44,44\% dos docentes são titulados pela PUC-SP; $11,11 \%$ dos docentes são titulados pela UFRJ; UFPB: $15,38 \%$ dos docentes são titulados pela UFPE; $11,54 \%$ dos docentes são titulados pela USP; UFAL: $44,44 \%$ dos docentes são titulados pela UFPE; $11,11 \%$ dos docentes são titulados pela UFSC; UFPE: $60,61 \%$ dos docentes são titulados pela UFPE; $9,09 \%$ dos docentes são titulados pela USP; UFS: 46,15\% dos docentes são titulados pela PUCSP; $15,38 \%$ dos docentes são titulados pela USP; UFC: 23,81\% dos docentes são titulados pela UFPE; $23,81 \%$ dos docentes são titulados pela PUC-SP; UFMA: $33,33 \%$ dos docentes são titulados pela PUC-SP; $20 \%$ dos docentes são titulados pela UFSC; UFRN: $33,33 \%$ dos docentes são titulados pela UFPE; $23,81 \%$ dos docentes são titulados pela PUC-SP; ${ }^{16}$

Nas conclusões, o autor enfatiza que a Pós-Graduação brasileira é regional, além do que não há nenhuma universidade que demonstre ter influência dominante em âmbito nacional.

A segunda das contribuições é a de Gameiro e Guimarães Filho, ${ }^{17}$ onde buscam mostrar como está estruturada a Pós-Graduação stricto sensu em Direito. Na sequência estabelecem que o estudo da rede de Pós-Graduação de Direito no Brasil permite revelar os cursos e programas que possuem maior capacidade de impactar ou de influenciar os demais.

16 VARELLA, Marcelo. Quem influencia a pós-Graduação em Direito no Brasil? Uma análise empírica da nucleação acadêmica. Revista de Direito Brasileira, v. 12, OP. cit. p.118, 2015.

17 GAMEIRO, Ian Pimentel; GUIMARÃES FILHO, Gilberto. O mapa da pós-graduação em Direito no Brasil: uma análise a partir do método da Social Network Analysis. v. 13 n. 3, 2018. Disponível em: http:// bibliotecadigital.fgv.br/ojs/index.php/revdireitogv/article/view/73332/70471. Acesso em: 23 nov. 2020. 
Salientam que o tamanho da rede contempla 94 programas (até 2016) e que os dados foram obtidos a partir da plataforma Sucupira. Explicam que utilizaram como método a análise de redes sociais.

Dentre os resultados parciais alcançados observaram o seguinte:

Como encontra-se a estruturada a rede de Pós-Graduação stricto sensu em Direito no Brasil;

Qual o programa de rede;

94 programas é o tamanho da rede (até 2016);

Dados: plataforma Sucupira/método: análise de redes sociais;

Resultados parciais;

(I) Rede irregular (desigualmente distribuída);

(I) Pouco densa;

(II) Fortemente orientada para as regiões sul e sudeste;

(III) Bastante regionalizada

Observam ainda que o programa que registrava maior capacidade de influenciar os demais era o da PUC-SP.

$\mathrm{Na}$ região Nordeste, restou evidenciado que a Universidade Federal de Pernambuco era predominante em quase todos os programas existentes, o que por si só evidencia que de fato o PPGD/UFPE registrou êxito, qualificando-se como um centro de influência regional, muito mais relevante do que outros grandes programas do Sudeste na construção de uma escola com influência regional, mais do que outras grandes do Sudeste.

Portanto, até o ano de 2016, segundo os dados obtidos através da plataforma Sucupira, estavam em funcionamento realmente 94 programas de Pós-Graduação em Direito. É relevante ressaltar que à época 1.824 professores estavam vinculados a esses programas na condição de membros permanentes. Os autores do relatório reconhecem que o número de docentes seria superior ao mencionado se fossem adicionados colaboradores e visitantes ou se fossem criados novos programas.

É importante também notar que a distribuição nacional desses programas e em consequência dos seus docentes, registra características de irregularidade e desigualdade em todo o âmbito nacional. Como era previsível, a região Sudeste é a que acumula o maior número de programas e de docentes. O gráfico 1 ilustra em percentuais as considerações ora efetuadas.

Com efeito, a distribuição destes programas e, naturalmente, dos seus docentes permanentes é bastante irregular e desigual ao longo das regiões do país. A região Sudeste é, de longe, a que concentra o maior número de programas e de docentes, seguida das regiões Sul, Nordeste, Centro-Oeste e Norte. O Gráfico 1 ilustra, em percentuais, a concentração de docentes por região do país. 


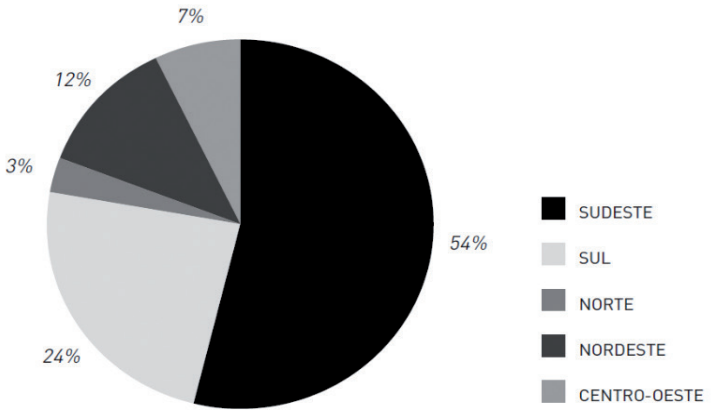

Fonte: Dados coletados na Plataforma Sucupira (2016).

(Elaborado por: Gameiro e Guimarães Filho) ${ }^{18}$

Os autores, após o registro dos dados quantitativos, passaram para a etapa na qual a dimensão a ser revelada é qualitativa da rede de Pós-Graduação stricto sensu em Direito no Brasil. Conforme consta no Gráfico 4 abaixo a rede aparece articulada com seus atores e liames que cada um dos programas mantém com os demais.
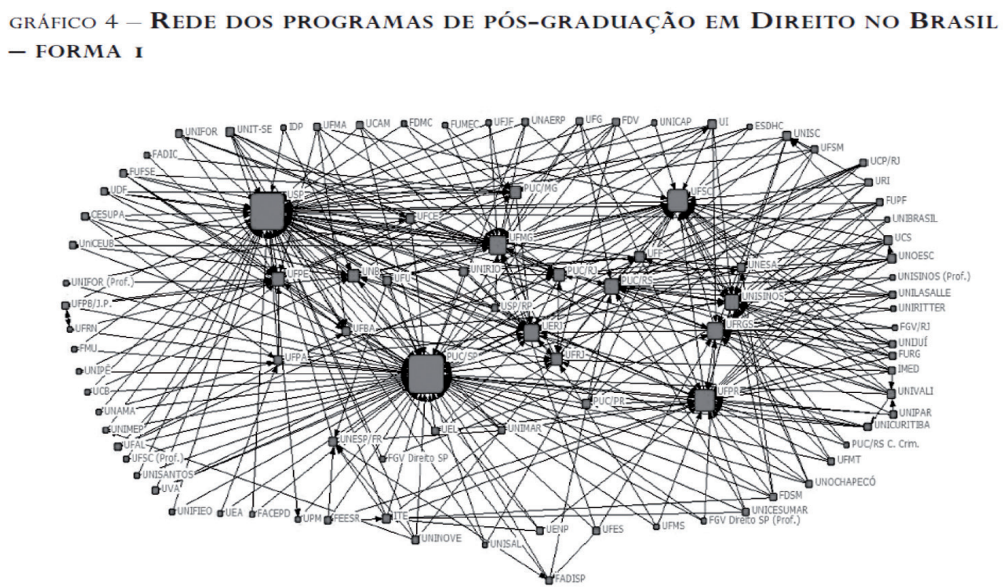

Fonte: Dados coletados na Plataforma Sucupira (2016).

(Elaborado por: GAMEIRO e Guimarães Filho) ${ }^{19}$

18 GAMEIRO, Ian Pimentel; GUIMARÃES FILHO, Gilberto. O mapa da Pós-graduação em Direito no Brasil, cit., p. 899.

19 GAMEIRO, Ian Pimentel; GUIMARÃES FILHO, Gilberto. O mapa da Pós-Graduação em Direito no Brasil, cit., p. 902. 
Por outro lado, como é possível observar, um dado emerge salientando a existência de "uma conectividade moderada entre os programas", conforme demonstrado no gráfico 5 abaixo. ${ }^{20}$

\section{GRÁFICO 5 - REDE dos PROGRAMAS DE PÓS-GRAdUAÇÃo EM DiREITO NO BRASIL}

\section{- FORMA 2}

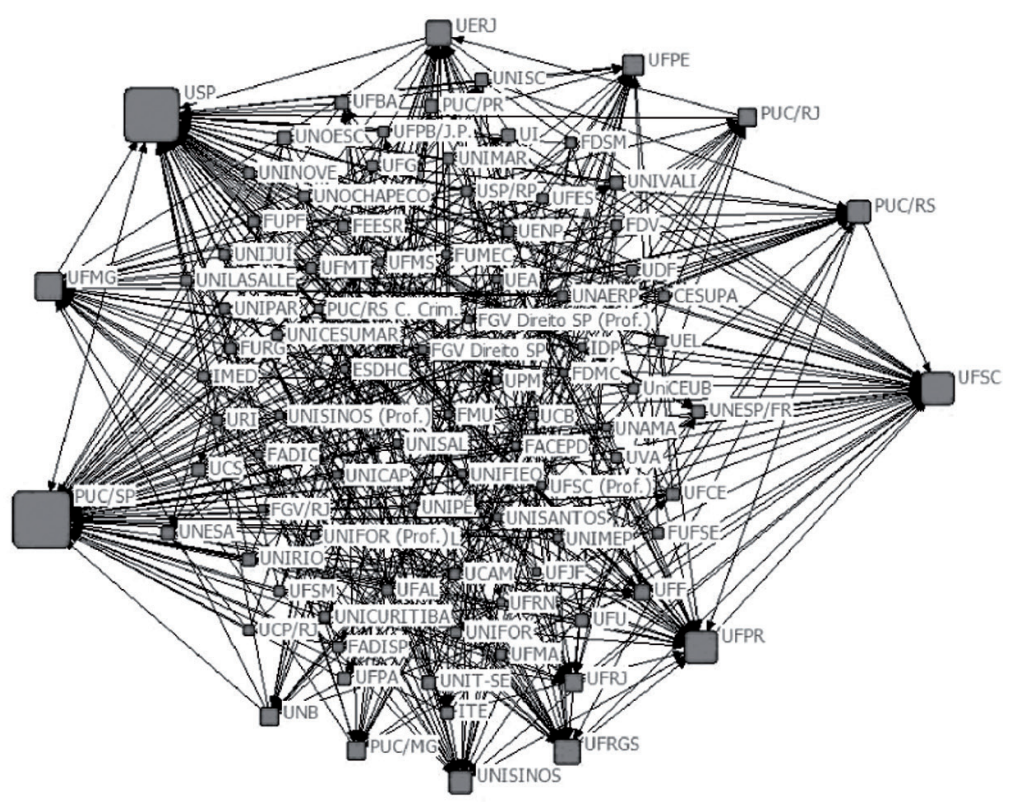

Fonte: Dados coletados na Plataforma Sucupira (2016).

(Elaborado por: GAMEIRO e Guimarães Filho) ${ }^{21}$

Como se constata, a PUC-SP e a USP surgem como as mais centrais. Tal centralidade significa que a PUC-SP e a USP se constituem nas instituições de ensino que mais tiveram seus egressos assimilados como membros permanentes de outros programas de Pós-Graduação stricto sensu em Direito. Em consequência, é possível admitir que são as instituições que mais estariam aptas a exercer influência sobre o conhecimento jurídico no Brasil. O Quadro número 1 a seguir apresenta os 20 programas mais centrais da rede. ${ }^{22}$

\footnotetext{
$20 \quad$ Idem, ibidem, p.903.

21 Idem, ibidem, p. 903.

22 Idem, ibidem, p. 904. 
QUADRO 1 - ÍNDICE DE CENTRALIDADE DOS PROGRAMAS DE PÓS-GRADUAÇÃO EM DIREITO NO BRASIL

\begin{tabular}{ll} 
PROGRAMA & ÍNDICE (\%) \\
\hline PUC-SP & 68,8 \\
\hline USP & 64,5 \\
\hline UFPR & 33,3 \\
\hline UFSC & 33,3 \\
\hline UFMG & 25,8 \\
\hline UNISINOS & 21,5 \\
\hline UFRGS & 21,5 \\
\hline UERJ & 19,4 \\
\hline PUC-RS & 16,1 \\
\hline UFPE & 16,1 \\
\hline UFRJ & 11,8 \\
\hline UNB & 11,8 \\
\hline PUC-RJ & 11,8 \\
\hline PUC-MG & 9,7 \\
\hline UFF & 6,5 \\
\hline UNESP-FRANCA & 5,4 \\
\hline ITE & 5,4 \\
\hline UNESA & 4,3 \\
\hline UFBA & 4,3 \\
\hline PUC-BR & 3,2 \\
\hline
\end{tabular}

Fonte: Dados coletados na Plataforma Sucupira (2016)

(Elaborado por: Gameiro e Guimarães Filho) $^{23}$ 
A região Nordeste do Brasil representa a terceira maior rede de PósGraduação stricto sensu em Direito, e estava estruturada em 14 programas e cerca de 220 docentes. À época da pesquisa de Gameiro e Guimarães Filho, o estado do Piauí não possuía programa de Pós-Graduação stricto sensu em Direito. Constatava-se também que Pernambuco e Ceará concentravam o maior número de programas, cada um deles com 3. Presentemente o Ceará possui 4 programas. O Gráfico 8 abaixo, evidencia a forma da rede referida. ${ }^{24}$

\section{GRÁFICO 8 - REDE DOS PROGRAMAS DE PÓS-GRAdUAÇÃo EM DiREITO NA REGIÃo NORDESTE DO BRASIL}

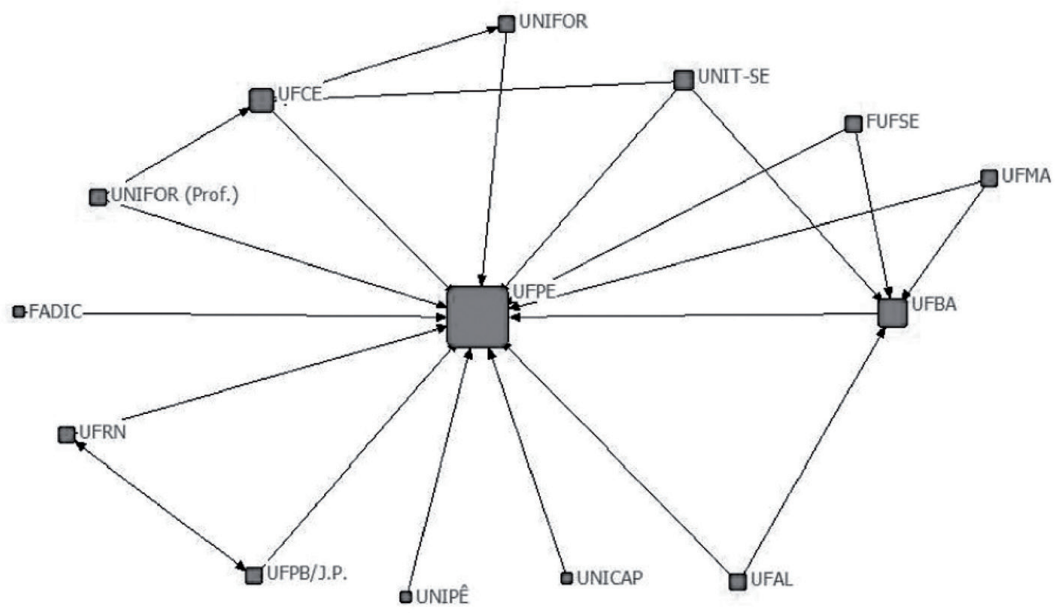

Fonte: Dados coletados na Plataforma Sucupira (2016).

(Elaborado por: Gameiro e Guimarães Filho) ${ }^{25}$

Nota-se que a rede de Pós-Graduação stricto sensu em Direito da região Nordeste mostra 22 interações entre os seus 14 programas. É possível verificar por meio do Gráfico 8 que se trata de uma rede com um único ator central:

O programa de pós-graduação em Direito da Universidade Federal de Pernambuco (UFPE), com índice de centralidade de $100 \%$. Isto significa que os demais programas existentes na região possuem pelo menos um docente doutorado

\footnotetext{
24 Idem, ibidem, p. 909.

25 Idem, ibidem. 
naquela instituição, de modo que a sua possibilidade de influenciar os demais a nível regional é máxima. ${ }^{26}$

Seja como for, é fato também que o PPGD/UFPE demonstra absorver como membros permanentes dos programas de Pós-Graduação stricto sensu em Direito seus antigos alunos de doutoramento. Tanto assim que na base de dados da Plataforma Sucupira entre os seus 25 professores permanentes, nada menos que 20 obtiveram o doutorado na mesma UFPE.

Concluem os autores que, pela análise realizada é possível constatar a centralidade de um programa nessa rede de Pós-Graduação stricto sensu no Brasil.

No mais, embora seja mediana a oferta formativa existente na região, tratase de uma rede altamente regionalizada e centralizada em um único ator, diferentemente do que se passa em outras regiões.

Em suma, podemos perceber que a centralidade de um programa na rede de Pós-Graduação stricto sensu em Direito do Brasil, e assim a sua capacidade de influenciar outros programas, encontra-se intimamente vinculada com o seu tempo de permanência na rede com a avaliação recebida pelo órgão regulador do Estado.

4. A nucleação na Pós-Graduação stricto sensu em Direito: o protagonismo e a solidariedade do PPGD/UFPE no Nordeste

Em 2014, um grupo de pesquisadores, com predomínio da área de educação, realizou um estudo sobre a formação do docente que atua no bacharelado em Direito. Tal pesquisa joga luz sobre um aspecto mais amplo da importância de alguns programas de Pós-Graduação stricto sensu em Direito, nos âmbitos local, regional e até mesmo nacional.

O estudo em questão foi estruturado a partir de uma abordagem "quali/ quanti", tento como base os dados fornecidos pelos programas de Pós-Graduação reconhecidos pela CAPES. As informações foram também pelos dados existentes no Coleta/CAPES.

26 Idem, ibidem. 
A fundamentação teórica da investigação ora citada, está estruturada em obrasdePrado, Santos, PereiraJúnior, ${ }^{27}$ Bittar, ${ }^{28}$ Ghirardi, ${ }^{29}$ Muraro, ${ }^{30}$ Pimenta,${ }^{31}$ Feferbaum, ${ }^{32}$ Bastos, ${ }^{33}$ entre outros.

No âmbito regional, o PPGD/UFPE formou:

(I) Recursos Humanos que desenvolveram atividades de ensino e pesquisa em instituições de ensino no estado de Pernambuco (capital e interior), levando a uma efetiva descentralização de "conhecimentos".

(II) Mestres e Doutores, que foram sendo utilizados em instituições públicas e privadas. Os Doutores, em especial conduziram a nucleação com novos PPGD.

(III) Com a participação de professores visitantes/colaboradores, notadamente no período de 2000 a 2010. Como exemplo citamos os professores: Fernando Scaff $^{34}$ (a época UFPA, hoje USP), Andreas Krell (UFAL), Paulo Lobo (UFAL e hoje na UFPE), Eduardo Ramalho Rabenhorst (UFPB). O PPGD/UFPE contou também com professores de outros programas de Pós-Graduação da UFPE destacando Luciano Oliveira (Sociologia/Ciência Política) e Michel Zaidan (História/Ciência Política).

(IV) Em especial, no período 2000 a 2010, membros do PPGD/ UFPE, assumiram relevantes funções em instituições de pesquisa (CNPQ) e Pós-Graduação (CAPES), inclusive na instituição que congrega os programas da área no país (CONPEDI), bem como na condução de representantes da área em agências públicas como CNPQ.

27 PRADO, Edna Cristina do; SANTOS, Clélia Maria dos; PEREIRA JÚNIOR, Antônio Miguel. Pósgraduação stricto sensu em Direito: onde e como se forma o docente dos cursos de graduação. $R B P G$, Brasília, v. 12, n. 28, p. 447, agosto de 2015.

28 BITTAR, E. C. B. Estudos Sobre Ensino Jurídico: pesquisa, metodologia, diálogo e cidadania. 2. ed. São Paulo: Atlas, 2006.

29 GHIRARDI, J. G. $O$ instante do encontro: questões fundamentais para o ensino jurídico. São Paulo: Fundação Getúlio Vargas, 2012.

30 MURARO, C. C. A formação do professor de direito. Revista Âmbito Jurídico, Rio Grande, v. 13, n. 73, fev. 2010.

31 PIMENTA, S. G.; ANASTASIOU, L. das G. C. Docência no Ensino Superior. São Paulo: Cortez, 2002.

32 VIEIRA, O. V. Desafios do ensino jurídico num mundo em transição: o projeto da Direito GV. In: FEFERBAUM, M.; GHIRARDI, J. G. Ensino do direito para um mundo em transformação. São Paulo: Fundação Getúlio Vargas, 2012.

33 BASTOS, A. W. O ensino jurídico no Brasil. 2. ed. Rio de Janeiro: Lúmen Júris, 2000.

34 No mesmo sentido ver: SCAFF, Fernando Facury. Orçamento republicano e liberdade igual: ensaio sobre Direito Financeiro, República e Direitos Fundamentais no Brasil. Belo Horizonte: Fórum, 2018, p. 285. 


\section{Projetos Minter e Dinter:}

Nesta parte, investigamos o papel e mesmo a influência de acordos interinstitucionais que tornaram possíveis a expansão do sistema nacional de Pósgraduação no Brasil. Como bem acentuam Flavia Moraes (UFRGS) e Maria Rosa Schetinger (UFSM), ${ }^{35}$ tais projetos representam efetivamente, uma flexibilização do sistema de Pós-graduação, dado que a partir de tais acordos, uma instituição denominada promotora, oferece uma contribuição para a expansão do sistema nacional de Pósgraduação no Brasil (2019). A Universidade Federal de Pernambuco oferece os cursos de mestrado e doutorado em Direito, atualmente ambos avaliados com nota quatro pela CAPES, no período de 2000 à 2010 a avaliação do programa obtinha a nota 5 . A formação de pesquisadores sempre foi o objetivo principal do programa, ainda que insira como objetivos também a formação de pessoal com alta qualificação para o ensino do Direito.

O programa promoveu ao correr do tempo reforma na estrutura das áreas de concentração bem como das linhas de pesquisa. Seus docentes seguem majoritariamente um perfil técnico com formação nas áreas jurídicas. Cumpre ressaltar que o programa agrega também professores com formação diversa:

O professor Michel Zaidan Filho possui graduação em filosofia, mestrado em história e doutorado em história social; o professor José Luciano Gois de Oliveira possui mestrado e doutorado em sociologia; o professor George Browne Rego é bacharel e Ph.D. em filosofia e o professor Torquato da Silva Castro Júnior é doutor em filosofia do direito e do Estado. ${ }^{36}$

\section{Conclusões}

De plano, cabe assinalar que o sistema nacional de Pós-Graduação no Brasil possui reconhecimento por parte da comunidade científica nacional e internacional. Certamente que tal reconhecimento rende homenagens aos padrões de seriedade, que foram direcionados ao padrão de qualidade no correr do tempo, desde a sua implementação até o presente momento.

35 MORAES, Flávia Melissa de Souza. Projetos DINTER: contribuição para a expansão do Sistema Nacional de Pós-Graduação. Porto Alegre, 2019. Disponível em: https://www.lume.ufrgs.br/handle/10183/196548. Acesso em: 25 nov. 2020.

36 ALMEIDA, Elizangela Santos de. A formação stricto sensu dos professores dos cursos de direito e seus reflexos no ensino jurídico. Dissertação (Mestrado em Educação) - Universidade de Uberaba - UNIUBE, Uberaba, 2014, p. 89. 
Tal como demonstrado no quando $n^{\circ} 1$ (Capítulo $1^{\circ}$ ), nos anos 60 estavam instalados e em funcionamento cerca de 38 cursos. Já em 2008 alcançavam a cifra de 2.558. E chegávamos em 2017, data da última trienal, avaliada nada menos que 4.581 .

Foi possível, igualmente, constatar que as políticas educacionais, voltadas para o ensino superior, com destaque para a Pós-Graduação stricto sensu, como ocorre com outros segmentos, apesar de sua expansão, como reconhecido, foi afetada por rupturas e permanências, mesmo considerando os 40 anos de PNPG (Plano Nacional de Pós-Graduação - o último compreende 2011-2020).

Os diversos estudos analisados admitem com razoável consenso que só mais recentemente assumiu protagonismo a questão da avaliação, especialmente por considerarmos que a distribuição dos programas pelo território nacional se deu de forma bastante desigual, em número e certamente na qualidade.

Portanto, a construção e expansão da Pós-Graduação no Brasil, conforme demonstrado, estava em processo de consolidação, evidentemente que passando por momentos marcados pela carência de recursos financeiros. Mas, como já enfatizamos, colocando esforços consideráveis na avaliação, em especial no que se refere a internacionalização e em situações limites lutando contra a concentração regional.

Por conseguinte, a Pós-graduação em Direito passou pelas mesmas dificuldades que as demais áreas, provavelmente com desafios bem maiores. Contudo, veremos que ao analisarmos uma espécie de mapa da Pós-Graduação em Direito stricto sensu no Brasil é razoável admitir que o processo de expansão e nucleação foi marcado por solidariedade, como política específica de alguns programas. É importante registrar o papel da representação de área do Direito no processo de expansão e nucleação. Especial registro deve ser fixado no período em que a representação foi exercida pelo professor Fernando Facury Scaff.

No caso em estudo, como já demonstrado, o destaque vai para o PPGD/ UFPE. No período entre 1996 a 2006, quando a Coordenação foi exercida pelos Professores João Maurício Adeodato, Francisco Queiroz, Raymundo Juliano, George Browne Rego. 